\title{
The Connection between the Southern Annular Mode and a Feature-Based Perspective on Southern Hemisphere Midlatitude Winter Variability
}

\author{
Clemens Spensberger AND Michael J. Reeder \\ Geophysical Institute, University of Bergen, and Bjerknes Centre for Climate Research, Bergen, Norway, \\ and ARC Centre for Climate Extremes, Monash University, Melbourne, Victoria, Australia \\ THOMAS SPENGLER \\ Geophysical Institute, University of Bergen, and Bjerknes Centre for Climate Research, Bergen, Norway \\ MATTHEW PATTERSON \\ Department of Physics, University of Oxford, Oxford, United Kingdom
}

(Manuscript received 25 March 2019, in final form 31 July 2019)

\begin{abstract}
This article provides a reconciling perspective on the two main, but contradictory, interpretations of the southern annular mode (SAM). SAM was originally thought to characterize meridional shifts in the storm track across the entire hemisphere. This perspective was later questioned, and SAM was interpreted as a statistical artifact depending on the choice of base region for the principal component analysis. Neither perspective, however, fully describes SAM. We show that SAM cannot be interpreted in terms of midlatitude variability, as SAM merely modulates the most poleward part of the cyclone tracks and only marginally influences the distribution of other weather-related features of the storm track (e.g., position of jet axes and Rossby wave breaking). Instead, SAM emerges as the leading pattern of geopotential variability due to strong correlations of sea level pressure around the Antarctic continent. As SAM correlates strongly both with the pan-Antarctic mean temperature and the meridional heat flux through $65^{\circ} \mathrm{S}$, we hypothesize that SAM can be interpreted as a measure of the degree of the (de)coupling between Antarctica and the southern midlatitudes. As an alternative way of characterizing southern midlatitude variability, we seek domains in which the leading EOF patterns of both the geopotential and storm-track features yield a dynamically consistent picture. This approach is successful for the South Pacific. Here the leading variability patterns are closely related to the Pacific-South America pattern and point toward an NAO-like variability.
\end{abstract}

\section{Introduction}

Southern Hemisphere midlatitude variability is commonly characterized by the southern annular mode (SAM; Limpasuvan and Hartmann 1999). Although SAM was originally defined using the mean pressure differences between observation stations along the Antarctic coast line and scattered stations around $40^{\circ} \mathrm{S}$ (Marshall 2003), it is now more widely defined as the leading EOF in the Southern Hemisphere of sea level pressure or geopotential in either the lower or upper troposphere (Thompson and Wallace 2000, and references therein). Some authors have questioned whether

\footnotetext{
Corresponding author: Clemens Spensberger, clemens.spensberger@ uib.no
}

SAM carries physical meaning (Gerber and Vallis 2005; Gerber and Thompson 2017), but one suspects that the original definition based on station observations resulted from on a subjective yet physically based intuition.

Associating an EOF pattern with physical meaning is far from straightforward. Even the comparatively clearcut example of the North Atlantic Oscillation (NAO) required considerable effort before a consistent conceptual picture emerged (e.g., Thompson and Wallace 2000; Ambaum et al. 2001; Feldstein 2003; Franzke et al. 2004; Woollings et al. 2008). Substantial progress toward this picture was achieved by associating the NAO with variations of features in the storm track, such as blocking and Rossby wave breaking (Franzke et al. 2004; Woollings et al. 2008). With this approach, the 
conceptual understanding gained in synoptic meteorology was transferred to longer time scales to better understand patterns of variability on monthly and longer time scales.

This comparison with the NAO raises the question of whether SAM can also be interpreted in terms of variations in the dynamics of the Southern Hemisphere midlatitude storm track. Were this the case, we would expect clear variations in the occurrence of pertinent features of the storm track associated with variations in SAM. Such a clear variation has been documented for the zonal wind, which shifts poleward during the positive phase of SAM (e.g., Kidson 1988; Thompson and Wallace 2000; Thompson and Woodworth 2014). In contrast, eddy kinetic energy, a measure of the vigor of the storm track, is nearly independent of SAM (Thompson and Woodworth 2014), demonstrating that the relation between SAM and the storm track is not as clear-cut as the regressions of the zonal wind might suggest.

There are several further results that complicate a physical interpretation of SAM. First, Codron (2007), Barnes and Hartmann (2010), and Ding et al. (2012) document regional differences in the dynamics of SAM during winter and question the hemispheric symmetry implied in the annular mode structure. Second, Kidson (1988), Hoskins and Hodges (2005), Kidston et al. (2009), and Ding et al. (2012) documented seasonal variations in the shape and properties of SAM, as well as in the correlation of SAM with observed surface weather. Third, and potentially most seriously, Gerber and Vallis (2005) and Gerber and Thompson (2017) showed that an annular mode structure can result purely from the geometry of the chosen domain. In this case, SAM would be little more than a statistical artifact resulting from a statistically optimal juxtaposition of physically unrelated variability.

Nevertheless, SAM does explain some of the variance in surface weather for a few (populated) locations close to the southern storm track (e.g., Silvestri and Vera 2003; Hendon et al. 2007). The strongest correlations in temperature and precipitation are, however, confined to relatively small regions along, for example, the southern parts of the Australian and South American west coasts (Reason and Rouault 2005; Hendon et al. 2007; Kidston et al. 2009), and predominantly to austral summer (Hendon et al. 2007).

In this study, we test both contrasting interpretations of SAM as either a meridional shift of the southern storm track or a statistical artifact. To this end, we follow the approach that we found instructive for the NAO. First, we provide evidence that SAM arises from correlations in the sea level pressure and geopotential around the Antarctic continent and offer a physical explanation for these correlations. Second, we show that SAM cannot be interpreted in terms of variations in the spatial distribution of cyclone tracks, jet streams, and Rossby wave breaking in the midlatitudes and revisit the imprint of SAM on surface weather in the Southern Hemisphere midlatitudes. Finally, we present results from the South Pacific sector, where we find the variability patterns of geopotential and features of the storm track to yield a consistent dynamical picture. To limit the scope of this article, we will only consider austral winter, June-August (JJA).

\section{Data, methods, and definition of SAM}

We base our investigation on 6-hourly ERA-Interim reanalysis data for the period 1979-2014, interpolated to a horizontal resolution of $0.5^{\circ}$ (Dee et al. 2011). We use the data on preinterpolated selected pressure levels and the -2 PVU surface (where $1 \mathrm{PVU}=10^{-6} \mathrm{~K} \mathrm{~kg}^{-1} \mathrm{~m}^{2} \mathrm{~s}^{-1}$ ), as provided by the European Centre for Medium-Range Weather Forecasts (ECMWF). In this dataset, we detect Rossby wave breaking and jet axes using the algorithms of Rivière (2009) and Spensberger et al. (2017), respectively. These algorithms trace the overturning parts of the isentropes and pronounced wind speed maxima on the -2 PVU surface, respectively. In addition, we calculate the cyclone tracks using the University of Melbourne algorithm (Murray and Simmonds 1991a,b), in a configuration yielding consistent results with Simmonds et al. (2008), as reported through the IMILAST project (Option M10 in Neu et al. 2013). At its core, this cyclone detection algorithm identifies cyclones through local maxima in the Laplacian of sea level pressure. When interpreting the results based on cyclone detections, it is important to keep in mind that substantial differences between different available schemes have been reported (Neu et al. 2013), specifically for the subantarctic seas (Grieger et al. 2018). Although the occurrence of the storm track-features is detected in the 6-hourly data, in most of the calculations reported here the detection frequencies are averaged over one month.

We define SAM as the first EOF of monthly mean geopotential on $700 \mathrm{hPa}$ south of $20^{\circ} \mathrm{S}$ during austral winter (JJA; Fig. 1a). The input data to this and all following EOFs are area weighted using the square root of the cosine of latitude. This definition is identical to the one used by Hendon et al. (2007) and is generally consistent with other definitions in the literature (Thompson and Wallace 2000, and references therein).

Consistent with Kidson (1988), Kidston et al. (2009), and many others, we note a wavenumber-3 pattern superposed onto the annular mode structure of SAM during winter (Fig. 1a). Kidston et al. (2009) offer 

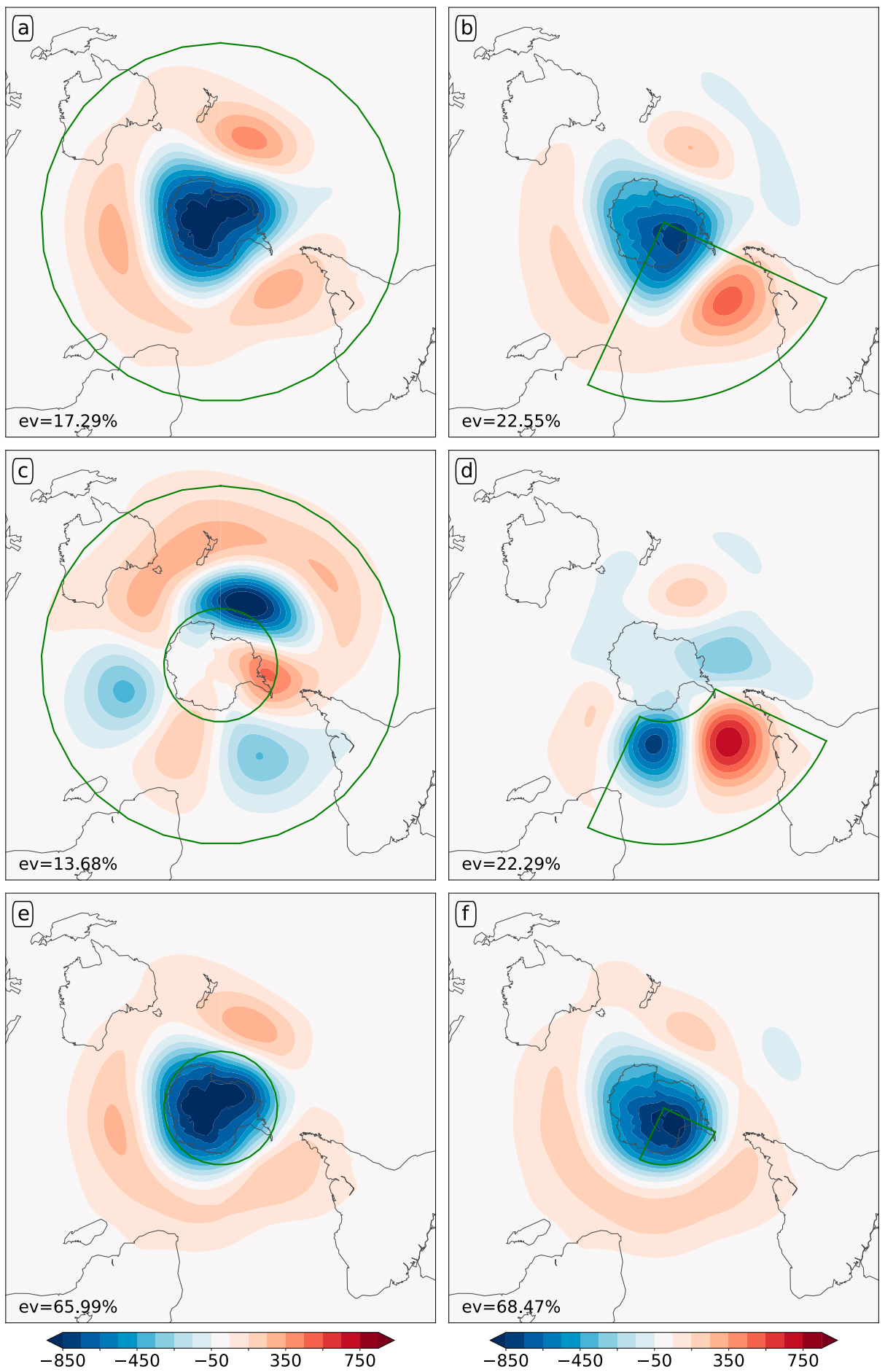

FIG. 1. Geopotential on $700 \mathrm{hPa}\left(\mathrm{m}^{2} \mathrm{~s}^{-2}\right)$ regressed onto the first EOF of $700 \mathrm{hPa}$ in the respective domains marked by the green contour.

elaborate hypotheses to explain two of the three stationary ridges through locally confined processes. Based on maps of cyclogenesis (not shown), we speculate that this wavenumber-3 pattern might be simply a result of three preferred regions of cyclogenesis, one located in each ocean basin. This speculation is largely consistent with the cyclogenesis results shown in Hoskins and Hodges (2005) and Wernli and Schwierz (2006). 

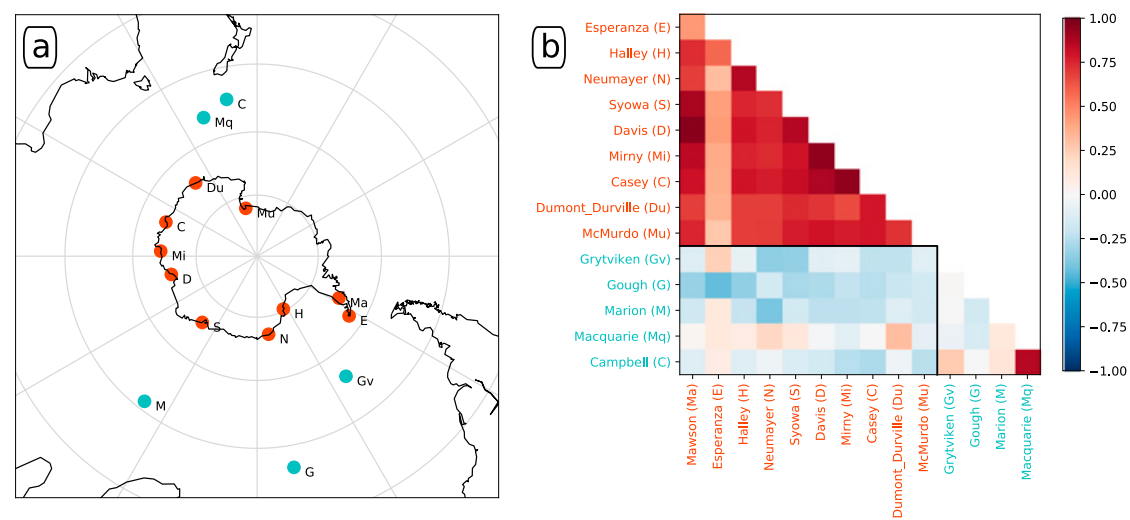

FIG. 2. (a) Map of stations used for the (b) correlation analyses of observed monthly mean sea level pressure. Cyan stations represent islands in the Southern Ocean, orange stations those located along the Antarctic coastline. The black lines in (b) hence separate the crosscorrelations amongst coastal stations (triangle upper left), among island stations (triangle lower right), and between island and coastal stations (rectangle lower left).

\section{The role of Antarctica in SAM}

\section{a. Origin of the annular mode structure}

Independent of the dynamical origin of the superposed wavenumber-3 pattern, the largely annular structure of the SAM pattern suggests some correlation of the variability between the different sectors. Hence, the annular mode structure should also appear as the result of an EOF analysis of a sufficiently large sector. Figure $1 b$ shows the results for an EOF analysis including only the South Atlantic sector. Despite the limited domain, the hemispheric regression of $700-\mathrm{hPa}$ geopotential onto this EOF still yields a hemispheric pattern that closely resembles that of SAM. The centers of action for the sector-based EOF are more emphasized in the Atlantic sector compared to the SAM pattern (Figs. 1a,b), but the overall structure and location of all lobes remain very much intact. This result applies also to sector-based EOFs for the Indian and Pacific sectors (not shown), indicating that there is clear covariability between different sectors. This covariability should not occur if SAM were a statistical artifact of the EOF analysis, and consequently these results already imply that SAM has a physical explanation.

When Antarctica is excluded from the EOF analysis, by excluding the area poleward of $65^{\circ} \mathrm{S}$, both the annular structure and the hemispheric correlations vanish from the geopotential-based EOFs (Figs. 1c,d). Consequently, the strong correlations in geopotential poleward of $65^{\circ} \mathrm{S}$ must be responsible for the hemispheric correlations.

The decisive role of Antarctica for the SAM pattern becomes even clearer when considering the inverse test. Limiting the domain to poleward of $65^{\circ} \mathrm{S}$ in the calculation of the EOFs, we recover the full SAM signal and hemispheric correlations in the geopotential pattern
(Fig. 1e). Even more strikingly, the hemispheric SAM pattern can be almost entirely recovered using only the tiny area south of $65^{\circ} \mathrm{S}$ in the Atlantic sector (Fig. 1f). Similar results are found for the other sectors (not shown). In fact, for the Indian Ocean sector $\left(65^{\circ}-90^{\circ} \mathrm{S}, 25^{\circ}-115^{\circ} \mathrm{E}\right)$, the leading and SAM-like EOF even accounts for $92 \%$ of the variability.

Station observations of monthly mean sea level pressure further underscore this result and provide clues to the potential physical mechanism for SAM. While there are very high correlations for stations scattered along the Antarctic coastline, the correlations between island stations in the southern midlatitudes are near zero (Fig. 2). In particular, there is little cross correlation between the sea level pressure at Marion Island, Gough, and Grytviken, which all are located under anticyclonic anomalies during the positive phase of SAM (Fig. 1a). Exceptions to the above are 1) the strong correlation between Macquarie Island and Campbell Island, which is due to their close proximity to each other; and 2) the weaker correlations between Esperanza and the remainder of the Antarctic coastal stations. However, Esperanza is situated at the tip of the Antarctic Peninsula, north of our cutoff at $65^{\circ} \mathrm{S}$, and is hence the coastal station most directly exposed to the southern storm track.

Recalling the original definition of SAM based on contrasting sea level pressure observations between coastal and island stations (e.g., Marshall 2003), Fig. 2 demonstrates that indices based on these observations will mainly be influenced by the coherent sea level pressure variations around Antarctica rather than the disparate variations at the island stations in the southern storm track. Hence, this observation-based definition of SAM also points to processes close to and over 
Antarctica as the physical explanations for this variability pattern.

The reason for the coherent variations in sea level pressure or geopotential captured in the SAM pattern is not immediately obvious. With the arguments of Gerber and Vallis (2005) and Gerber and Thompson (2017) in mind, the null hypothesis must be that this pattern is entirely due to what they call "statistical annularity," that is, little zonal variation in the statistics of geopotential variability. Were this true, SAM would arise due to an optimal statistical combination of independent variability in different locations.

The strong correlations in sea level pressure, however, cannot be explained by this hypothesis. It is not obvious why, for example, sea level pressure variations at Mawson are correlated with a coefficient exceeding 0.8 with sea level pressure variations at Davis around $4000 \mathrm{~km}$ away, near the opposite side of the Antarctic ice dome. Physical proximity seems like an implausible explanation for this correlation and thus calls for a physical explanation.

Further, the geopotential-based EOF for the annulusshaped domain covering the southern midlatitudes does not exhibit an annular structure (Fig. 1c), even though the statistical optimality argument of Gerber and Vallis (2005) and Gerber and Thompson (2017) should equally apply to this perfectly annular domain. For this EOF, however, zonal asymmetries introduced by the three partly separated ocean basins seem to lead to clear zonal asymmetries also in the geopotential variability. The annular structure of SAM can therefore result neither from statistical annularity nor from a physical process in the midlatitudes (cf. Figs. 1a,c). Either of these alternatives should yield an annular variability pattern also in the annulus-shaped domain.

Instead, the geopotential variability over Antarctica dominates the entire hemisphere (Fig. 1e), because it is so much more coherent (EOF1 explains nearly twothirds of the variance) than the geopotential variability in the mid- and lower latitudes. Again, the spatial coherence of the geopotential variations over Antarctica cannot be fully explained by statistical optimality, and hence calls for a physical explanation. Hence, while we cannot rule out that statistical optimality constraints of the EOF analysis contribute to the annular structure of SAM, it seems very unlikely that statistical effects are the main reason behind its appearance.

\section{b. Physical interpretation}

With the strong correlations in sea level pressure and geopotential along the Antarctic coastline and over the Antarctic continent, it seems natural to start looking at these locations for a physical process leading to this pattern.

The dominant pattern of geopotential variability is largely independent of the vertical level chosen for the definition of SAM. The pattern even extends well into the stratosphere, following an equivalent barotropic structure (e.g., Thompson and Wallace 2000). The equivalent barotropic structure implies both a redistribution of mass on the continental scale between SAM phases, and a cold anomaly associated with the positive (cyclonic) phase of SAM.

Indeed, we find the average temperature at $700 \mathrm{hPa}$ south of $65^{\circ} \mathrm{S}$ to be highly correlated with SAM $(c=-0.72)$. With the heat loss over Antarctica largely determined by outgoing longwave radiation, the heat transport toward Antarctica must set these temperatures on the continental scale. This deduction is supported by the correlation between SAM and the zonal-mean poleward heat transport, because the maximum correlation occurs at around $65^{\circ} \mathrm{S}\left(c_{\max }=-0.55\right)$. In contrast, the heat flux shows weakly positive correlations throughout most of the midlatitudes $\left(c \leq 0.25,35^{\circ}-55^{\circ} \mathrm{S}\right)$.

These two correlations suggest a potential physical explanation for SAM. Based on the heat flux, we speculate that SAM is a measure of the degree of thermal (de) coupling between Antarctica and the southern midlatitudes. During months of positive SAM (by convention corresponding to a cyclonic anomaly over Antarctica as shown in Fig. 1), Antarctica receives less heat from the midlatitudes and hence cools. Through geostrophic adjustment, the intensification of the circumpolar jet and increase of the associated step in the meridional PV profile, the (de)coupling process might even be selfamplifying. Dritschel and McIntyre (2008) show that a large step in the meridional PV profile constitutes a barrier for mixing processes, which could lead to a further reduction in the heat supply to Antarctica. This interpretation explains the coherent variations of observed sea level pressure along the Antarctic coastline and the geopotential variability in reanalyses, as well as the emphasis on variability near Antarctica in the cyclone track distribution and near-surface weather conditions. Hence, the interpretation is consistent with all results presented.

\section{The connection between SAM and cyclone tracks, jets, and Rossby wave breaking}

Previous studies that regard SAM as a physical pattern of variability typically interpret the pattern as a meridional shift of the southern storm track in tandem with an expansion or contraction of the polar cold pool (e.g., Kidson 1988; Thompson and Wallace 2000). Were this interpretation correct, we would expect a corresponding shift in the meridional distribution of cyclone tracks and jet axes, as both types of features align with the storm track. For wave breaking, we would expect a shift in the dominant type of wave breaking. For a poleward displaced storm track, we would expect more 


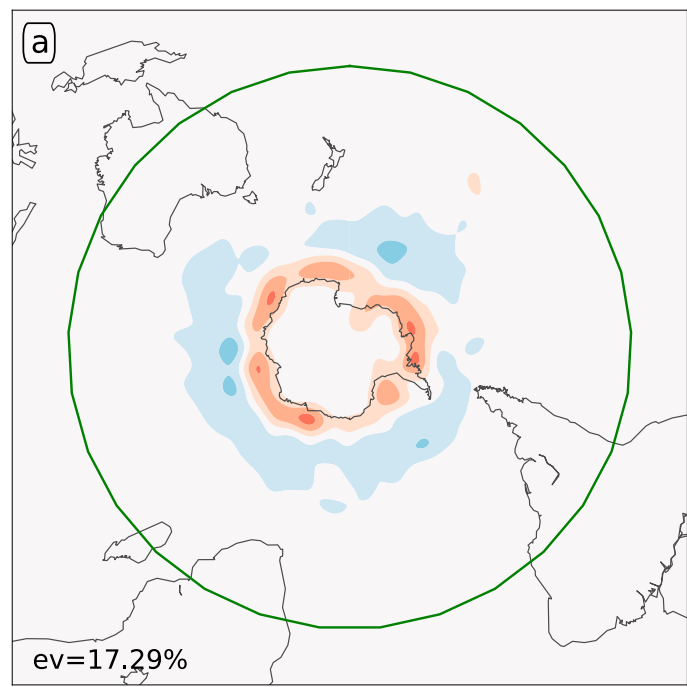

$-2.75-1.75-0.75 \quad 0.25 \quad 1.25 \quad 2.25$

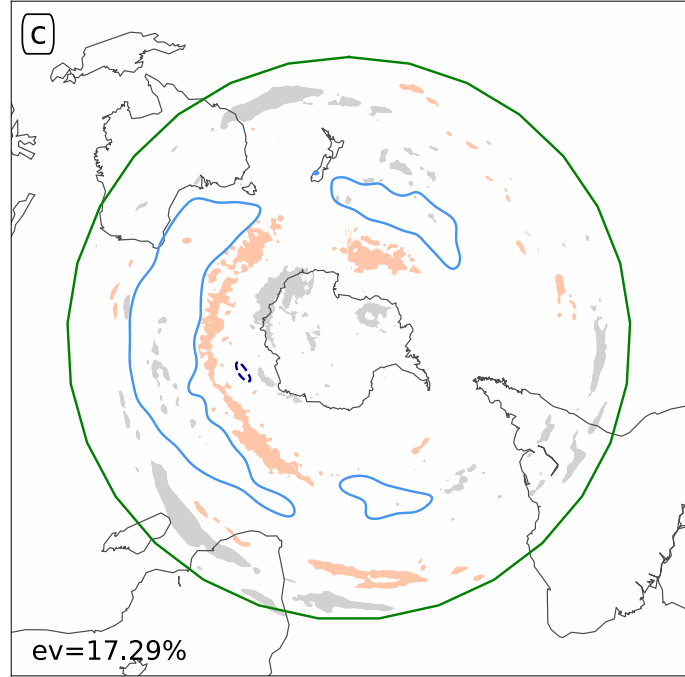

$-1.75-1.25-0.75-0.250 .250 .751 .251 .75$
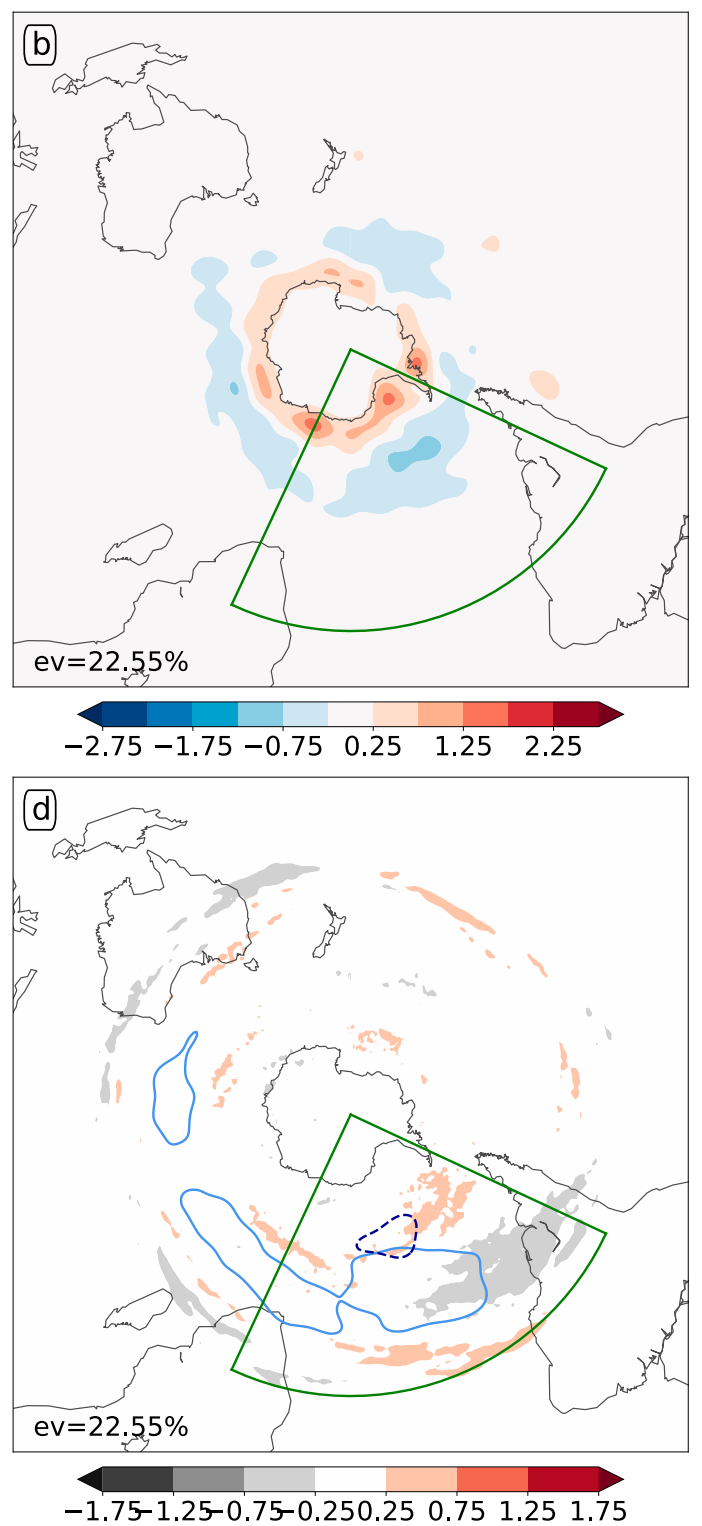

FIG. 3. (a), (b) Cyclone track densities in detections per $10^{6} \mathrm{~km}^{2}$ and 30 days, as well as (c), (d) jet axis distribution (shading, detections per 30 days) and wave-breaking frequencies (light blue contours: anticyclonic; dark blue contours: cyclonic; dashed contours indicate negative less frequent wave breaking) regressed onto (a), (c) SAM and (b), (d) the first EOF of $700 \mathrm{hPa}$ in the South Atlantic sector. The area marked green is used for the underlying EOF analyses. The contour interval for the wave-breaking frequencies in (c) and (d) is 0.75 detections per 30 days, with the zero contour omitted and negative contours stippled. The area marked green is used for the underlying EOF analyses. Note, to aid comparison between figures, we use the same color bar ranges throughout the paper, which for this figure yields only a very limited set of contours.

anticyclonic but less cyclonic wave breaking, and vice versa for an equatorward displaced storm track (Barnes et al. 2010; Barnes and Hartmann 2012).

Considering first the regression of the cyclone track distribution onto SAM, the positive phase of SAM is associated with more cyclones close to and along the Antarctic coastline (Fig. 3a). In addition, there is a weaker tendency for fewer cyclones at lower latitudes extending equatorward to about $45^{\circ}-50^{\circ} \mathrm{S}$. Over the temperate landmasses, the change in frequency of occurrence of cyclones remains close to zero. Although the dipole structure is consistent with a meridional shift in the cyclone track density, congruent with the correlations to zonal-mean heat fluxes, the emphasis of this dipole is on the variability close to the Antarctic coastline. 
Interestingly, and in contrast to the cyclone track density, the distributions of jet axes and wave breaking are only weakly correlated to SAM (Fig. 3c). The only exception to the otherwise incoherent and weak regressions is the increase of anticyclonic wave breaking during the positive phase of SAM in particular in the Indian Ocean sector (Fig. 3c). Further, the regressions do not become more coherent when the EOF domain is restricted to the South Atlantic sector (Fig. 3d). This insensitivity of the regressions to taking a sector for the EOF domain is consistent with the regressions for geopotential (Fig. 1a vs Fig. 1b) and the cyclone track density (Fig. 3a vs Fig. 3b).

The consistency between hemispheric and sector-based EOFs does not translate to EOFs based on the monthly mean distribution of storm-track features themselves (Fig. 4). The variability in the Atlantic sector does not correlate with variability in the other sectors for any of the considered features of the storm track (right column of Fig. 4). This discrepancy further questions the usual interpretation of SAM in terms of midlatitude variability, because it demonstrates that the correlations between sectors implied in the SAM pattern do not have an equivalent in the variability of storm-track features. Again, we have shown only results for the Atlantic sector, but these results translate also to the other sectors.

Although the hemispheric feature-based EOFs seem at first glance to be consistent with the SAM pattern, there are important differences. First, while the EOF of the cyclone track distribution is very similar to the regression onto the geopotential-based EOFs, the amplitude is about double that of the regressions (cf. Fig. 4a with Fig. 3a). Hence, geopotential variability explains only about half of the amplitude of this pattern of cyclone track variability.

The other features point more to a patchwork of variability around a spiraliform storm track, with different types of variability in the different sectors (Figs. 4c,e,g). Focusing first on jet variability, the subtropical jet dominates the variability patterns in the Indian Ocean and varies in meridional position around the climatological jet axis (Fig. 4c). In contrast, the variability pattern in the South Atlantic exhibits a clear tripolar structure around the climatological maximum wind, indicating that the dominant type of variability captures the difference between a straight jet locked in its climatological position and a more variable meandering jet. Woollings et al. (2018) demonstrated that this type of variability is associated with an intensification or weakening of the jet, because they find the strongest jets to be locked in their climatological positions but weaker jets to meander. The dominant pattern of variability in the Pacific sector marks the transition from dominant meridional shifts in the Indian Ocean toward dominant intensity variations in the
Atlantic sector. The pattern is thus a mixture of the dipole in the Indian Ocean and the tripole in the South Atlantic.

The dominant variability patterns of wave breaking (Figs. 4e,g) seem consistent with the jet axes-based interpretation of the storm-track variability. The lobes of wave-breaking variability generally occur where the theory of Barnes et al. (2010) and Barnes and Hartmann (2012) would predict them. Nevertheless, there is little temporal correlation between any of these variability patterns or SAM (not shown), demonstrating that the considered features of the storm track capture patterns of variability that are largely unrelated to each other and largely unrelated to SAM.

All these discrepancies between the different variables show that the relation between SAM and features of the storm track is much less clear-cut than one might have expected from the usual interpretation of SAM as a mode of midlatitude variability. The main reason for these discrepancies is the dominant role of Antarctica in the geopotential-based EOFs, discussed in the previous section. In contrast to geopotential, the inclusion or exclusion of Antarctica is inconsequential for EOFs based on feature distributions, because few cyclones, jets, and wave-breaking events are detected over the Antarctic continent (not shown).

In the following, we present several sensitivity tests with, among others, variants of the jet axis detection algorithms to test alternative hypotheses that might explain the observed discrepancies between the variability patterns of the geopotential and the storm-track features. All of these hypotheses need to be refuted and thereby support our conclusion that SAM is not capturing midlatitude storm-track variability.

\section{a. Varying the vertical level and type of detected jet}

Jet axes are detected at the level of the dynamical tropopause, whereas we use 700-hPa geopotential as the basis for our definition of SAM. However, jet detections at $700 \mathrm{hPa}$ do not show any correlation between sectors either, whereas geopotential in the mid- and upper troposphere does (tested for 300 and $500 \mathrm{hPa}$ ). These results also imply that the discrepancy regarding the correlation between sectors is not due to different hemispheric correlations of the variability of the subtropical jet dominating the upper troposphere and the variability of the eddy-driven jet captured in the lower troposphere.

\section{b. Varying the time averaging of the input data}

When calculating the EOFs of both the jet axis distribution and the geopotential, we use monthly means. While the monthly averaged geopotential smooths short-lived weather events, most such weather events are still visible in the monthly jet axis distribution due to 

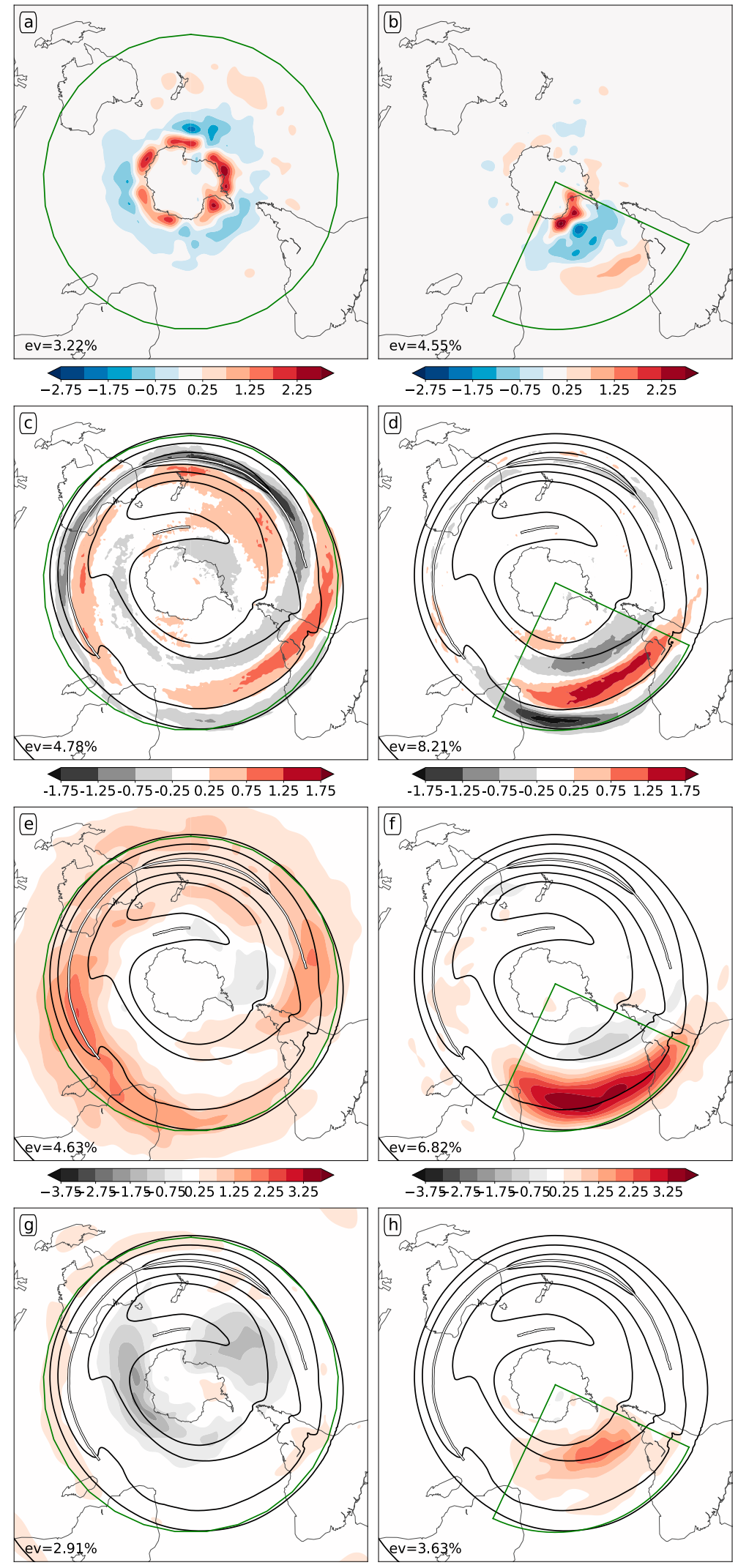

$-3.752 .75-1.750 .750 .251 .252 .253 .25$
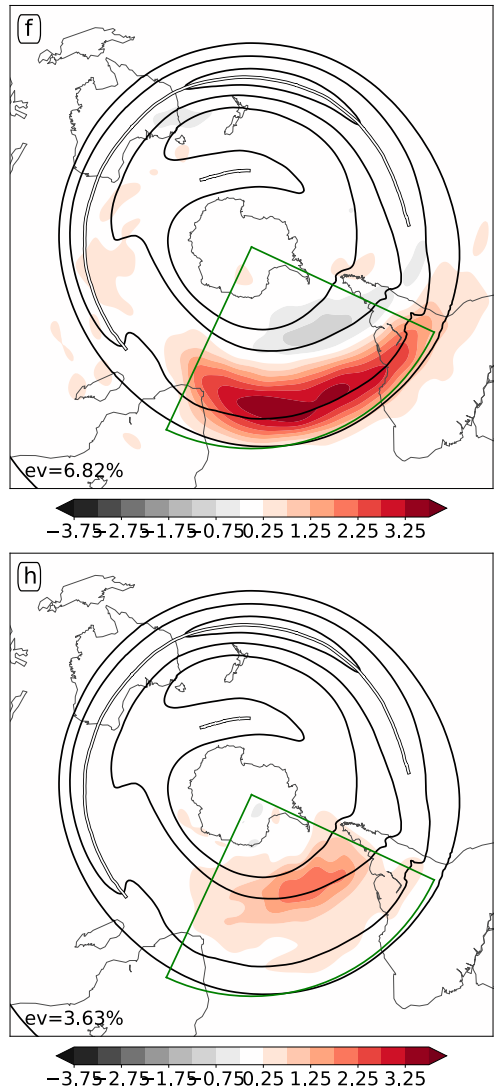
the spatially discrete nature of the jet axis lines. Hence, variations in short-lived weather events contribute to the jet axes-based EOF but not to the geopotentialbased EOF. This effect is particularly obvious for a wave-breaking event, where the inverted gradient in geopotential is invisible in the monthly mean. On the other hand, the meandering and overturning jet axis line associated with the wave-breaking event remains apparent in the monthly jet axis distribution.

If this difference in the effect of the time averaging were the reason behind the missing hemispheric correlations for the considered features of the storm track, we would expect this hemispheric correlation to vanish also in an EOF based on daily mean geopotential. This is, however, not the case; the SAM pattern and the hemispheric correlations remain also when we base our analysis on daily mean geopotential (not shown). The only difference between the hemispheric EOFs based on the daily mean and the monthly mean geopotential is the explained variance, which is $8.85 \%$ in the former and $17.29 \%$ in the latter.

\section{c. Including jet intensity in the EOF}

Another potentially decisive difference between geopotential and the jet axis lines is that the former is a measure of both the intensity and location of strong winds, while the jet axis lines only mark the location of the jet. This, however, cannot explain the missing hemispheric correlations in the jet axes-based EOFs either. We repeated our analysis weighting the jet axis detections by the wind speed at the respective location without change in our results.

\section{The connection between SAM and surface weather}

If SAM describes variability of the midlatitude storm track, we should, analogously to the NAO, expect a clear signature of the index on weather, for example, nearsurface winds and precipitation. Such correlations have been documented for austral winter, although they have been found to be considerably stronger during summer (e.g., Gillett et al. 2006; Hendon et al. 2007; Kidston et al. 2009; Hendon et al. 2014). In line with the results of these studies for winter, we find some signature of SAM in the regression onto these variables, for example in precipitation along the South American west and Antarctic coastlines (Fig. 5).

However, the overall magnitude of the precipitation and wind anomalies associated with SAM appears to be small. Due to the large intrinsic temporal variability of precipitation, most of the precipitation anomalies along the southern storm track are not significant. Except for a belt of surface wind anomalies along the Antarctic coastline, the magnitude of the wind anomalies remains well below $2 \mathrm{~m} \mathrm{~s}^{-1}$ (Fig. 5a). Although this belt around Antarctica generally exhibits an annular structure, there are zonal asymmetries in the wind anomalies of the opposite sign at lower latitudes. At lower latitudes, the strongest wind anomalies occur in the Indian Ocean and in a large-scale vortex just to the east of New Zealand (Fig. 5a). Precipitation anomalies associated with SAM typically remain below $10 \mathrm{~mm}$ month $^{-1}$ and, despite considerable small-scale noise, generally follow a relatively symmetric annular structure consistent with a meridional shift in precipitation.

It is interesting to note that despite the consistent appearance in the regressions onto 700-hPa geopotential and the considered storm-track features, the relative magnitude of the anomalies in the near-surface conditions differs considerably between SAM and the South Atlantic EOF (Fig. 5a vs Fig. 5b). For example, the anomalous westerlies in the Indian and Pacific sectors largely disappear, and a vortex in the South Atlantic sector that is hardly visible in the regressions based on the hemispheric EOF becomes the dominant wind anomaly in the sectorbased EOF. This sensitivity of the near-surface weather to the EOF domain questions the robustness of the reported impact of SAM on weather outside the belt of anomalous winds close to Antarctica.

Our hemispheric results are largely consistent with Hendon et al. (2007), who analyze wind anomalies at the 850-hPa level and find a very similar spatial distribution of the anomalies. Our results also agree in part with those of Kidston et al. (2009), in that we find the same signature in the low-level wind around New Zealand associated with SAM. However, Kidston et al. (2009) documents some correlation to observed precipitation at New Zealand weather stations during winter, whereas

FIG. 4. Each row is analogous Figs. 1a and 1b, but for EOFs of monthly (a), (b) cyclone tracks density (detections per 30 days and $10^{6} \mathrm{~km}^{2}$ ), (c), (d) jet axis detection frequency, (e), (f) anticyclonic wave-breaking frequency, and (g), (h) cyclonic wave-breaking frequency (all in detections per 30 days). Jets and wave breaking were detected on the PV2-surface. The black contours in all panels show the climatological wind speed on the PV2 (contours at 20,30, and $40 \mathrm{~m} \mathrm{~s}^{-1}$ ), and the white-black lines jet axes detected based on the climatological winds. 

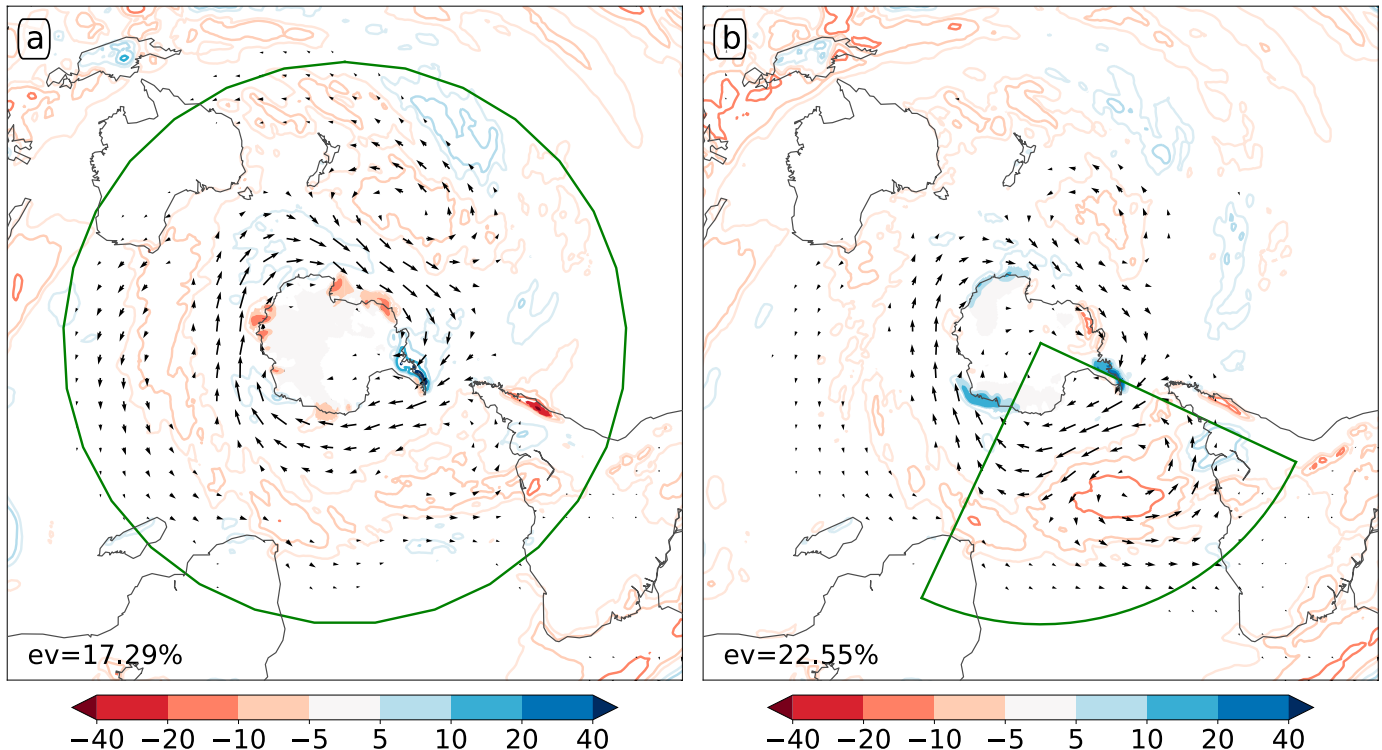

FIG. 5. Regressions of total precipitation (mm per 30 days) in filled and empty contours and the $10 \mathrm{~m}$-wind components (arrows) onto (a) SAM and (b) the first EOF of $700 \mathrm{hPa}$ geopotential in the South Atlantic sector. Significant regressions of total precipitation ( $95 \%$ level) are indicated by filled contours. Insignificant wind anomalies are omitted. The longest vectors in either panel correspond to about $3 \mathrm{~m} \mathrm{~s}^{-1}$. The area marked green is used for the underlying EOF analyses.

we hardly see any imprint of SAM in precipitation in this area. This difference is probably due to the use of station observations rather than reanalysis data. Kidston et al. (2009) also use a definition of SAM based on the 500-hPa geopotential rather than the 700-hPa level used in this study and Hendon et al. (2007). However, we do not find any precipitation anomalies over New Zealand using the leading EOF of 500-hPa geopotential instead of our SAM index.

Motivated by this difference between reanalysis and station observations, we complement our results with observations from a few locations around the southern storm track where one might expect a clear imprint of SAM (Punta Arenas in Chile, Perth and Melbourne in Australia, and Wellington in New Zealand; Fig. 6). With a few exceptions, for the four considered locations, the distributions of monthly mean daily minimum and maximum temperatures as well as monthly precipitation only depend weakly on SAM. The exceptions are precipitation in Punta Arenas and Perth, as well as daily minimum temperatures in Perth. ${ }^{1}$

Overall, the results from these station observations are, however, consistent and hence support our reanalysis-

\footnotetext{
${ }^{1}$ These parameters correlate with SAM with coefficients $0.41-$ 0.45 . In comparison, winter precipitation in Bergen, near the climatological terminus of the Atlantic storm track, correlates with the NAO with a coefficient of 0.60 .
}

based results. The clearest and most robust imprint of SAM on surface weather seems to be concentrated in a belt of wind anomalies around the Antarctic continent. In the mid- and lower latitudes, the imprint on winter weather is weaker and less coherent, supporting our earlier conclusion that SAM is not primarily capturing midlatitude variability.

\section{Alternative approaches to characterize SH midlatitude variability}

If we accept that SAM predominantly measures variability in the subpolar and polar regions, the question arises: is there a better way to characterize southern midlatitude variability? Motivated by the consistency between variability patterns in geopotential and stormtrack features, we use the NAO as guidance for our evaluations. Hence, the most useful result would be a domain for the EOF analysis, where the leading EOF patterns of all these variables are highly correlated and hence are likely due to the same underlying physical mechanism. Further, we would expect such a pattern to have a clear-cut relationship to surface weather.

Following our previous findings, we restrict our attention to variability patterns between $20^{\circ}$ and $65^{\circ} \mathrm{S}$ to avoid the dominating influence of Antarctica on the patterns. Further, for all of the feature-based EOFs as well as the geopotential-based EOFs between $20^{\circ}$ and $65^{\circ} \mathrm{S}$, the variability pattern in the Atlantic sector is a 

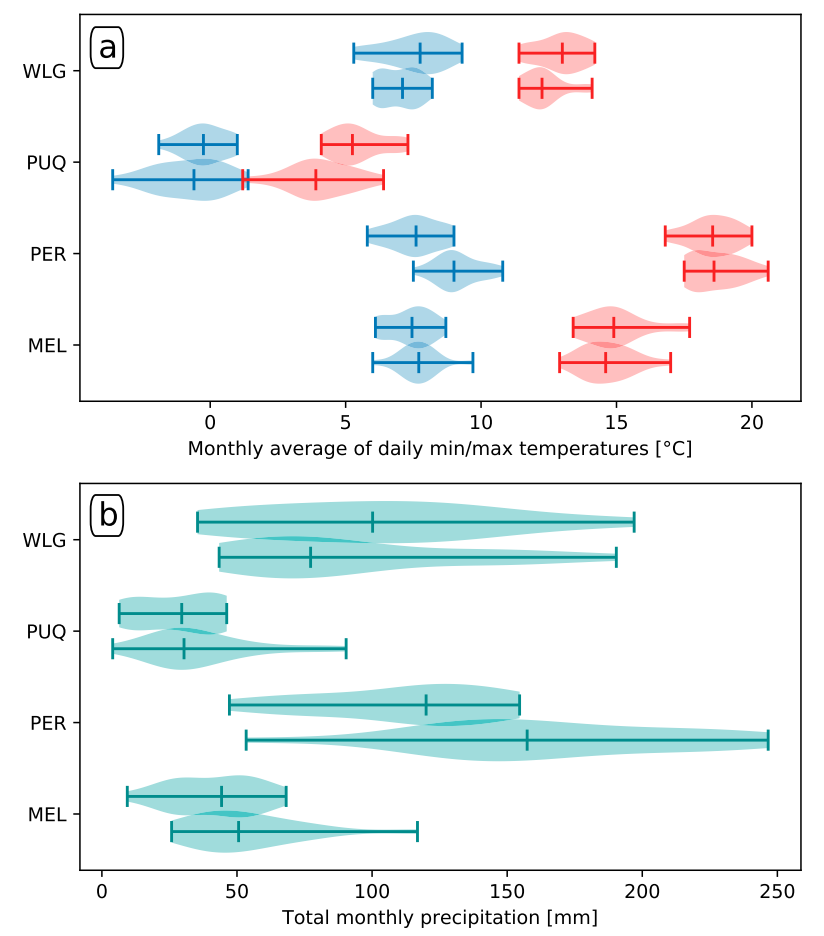

FIG. 6. Dependence of (a) the monthly average of daily minimum (blue) and maximum temperatures (red) and (b) total monthly precipitation on the phase of SAM for observations from (WLG) Wellington, (PUQ) Punta Arenas, (PER) Perth, and (MEL) Melbourne. The top (bottom) row for each pair of rows shows the distributions for the SAM index $\leq-1$ (SAM index $\geq 1)$. The vertical bars show the minimum, maximum, and median value of the distribution, and the filled areas ("violins") provide a rough estimate of the distribution. Note that despite the smooth appearance, each violin is only based on about 15 monthly values.

cutout of the respective hemispheric pattern (Figs. 1c,d and 4). This relation between the sector and the hemispheric pattern suggests that the hemispheric pattern is a statistical combination of unrelated variability in the different sectors, and likely entangles different processes and different types of variability in one pattern. For this reason, we consider variability patterns separately for each ocean sector.

Unfortunately, for both the Atlantic sector used in Figs. $1-5$ as well as the Indian Ocean sector $\left(25^{\circ}-115^{\circ} \mathrm{E}\right)$, the dominant patterns of geopotential and the stormtrack indices are hardly more correlated than for the EOFs including Antarctica shown earlier (Figs. 1a,b, 3, and 4). The imprint of these sector-based variability patterns on surface weather is, however, typically more pronounced and coherent than in Fig. 5 (not shown). Hence, to explain surface weather variations in these sectors, these patterns might provide valuable insight despite the inconsistency between geopotential and the storm-track features.
In contrast to the other sectors, the leading variability patterns of all considered variables are largely consistent in the South Pacific (Fig. 7). The dominant variability pattern appears as a clear dipole structure in the geopotential distribution, as well as a tripole in the jet axis distribution. The tripole in the jet axis distribution is centered between the subtropical and the eddy-driven jet, indicating that this tripole marks the difference between a state with a combined eddy-driven and subtropical jet between $40^{\circ}$ and $50^{\circ} \mathrm{S}$ and a state with a separate subtropical and eddy-driven jet on the respective sides of this band of latitudes. The state with two separate jets is associated with an increase in cyclonic wave breaking on the poleward side of the subtropical jet as well as a decrease in anticyclonic wave breaking on the equatorward side of the terminus of the combined jet (Figs. 7c,d). EOFs for anticyclonic wave breaking and the cyclone track distribution match the geopotentialbased EOF better than then the jet axes-based EOF (not shown).

With a temporal correlation of $69 \%$, this pattern is closely related to the first mode of the Pacific-South America (PSA) pattern (Lau et al. 1994). The two modes of the PSA are typically interpreted as representing a propagating wave train, and have been shown recently to be predominantly of midlatitude origin (O'Kane et al. 2017). This finding is consistent with the clear relation between variability of the geopotential and the stormtrack features that we documented for our variant of this pattern. Note, however, that this clear relation largely vanishes when using the established definition of PSA1 as EOF2 of the hemispheric geopotential-based EOFs. Further, we find no relation between storm-track features and PSA2 (i.e., EOF3), and a comparatively weak correlation of 0.42 to EOF2 in the Pacific sector.

The described variability pattern also leaves a clear imprint on the near-surface wind and precipitation (Fig. 8). The geopotential anomalies in the EOF in Fig. 7a are matched almost perfectly with pronounced and coherent

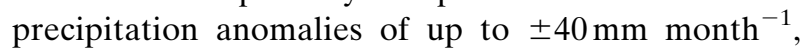
although only the southern precipitation anomaly is statistically significant. The near-surface wind anomalies close to the Antarctic coastline are similarly strong as the regressions in Fig. 5, but much stronger and more coherent in the midlatitudes and subtropics. In contrast to previous regressions, this pattern in the South Pacific is associated with significant wind anomalies even beyond the northern boundary of the EOF domain at $20^{\circ} \mathrm{S}$.

Our analyses do not provide enough evidence to support a speculation of what makes the South Pacific stand out in this analysis. The results of Ding et al. (2012) and Lachlan-Cope et al. (2001), however, might provide some indications. They point out that the South Pacific is special both in its forcing 

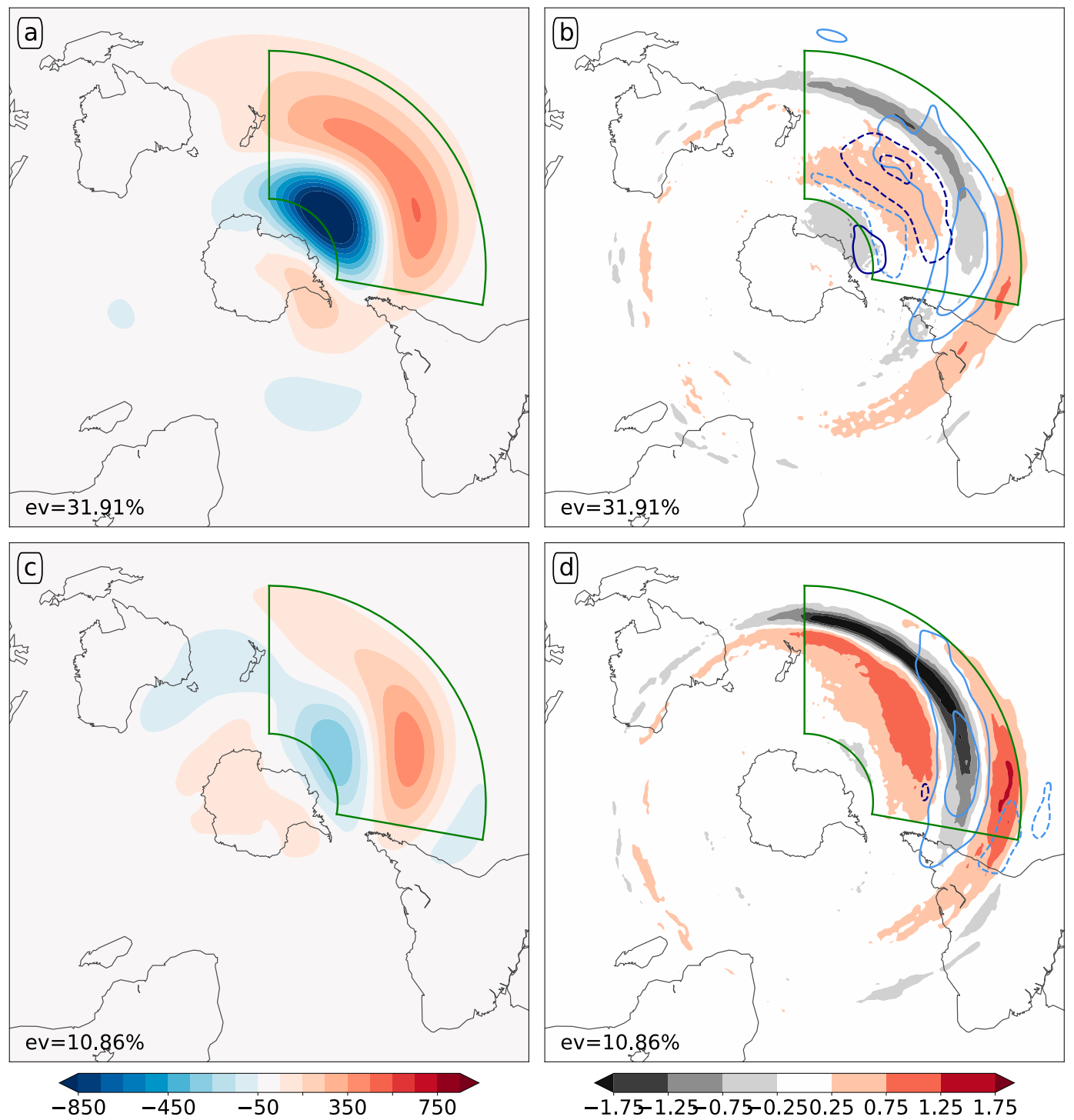

FIG. 7. Regressions of (a), (c) 700-hPa geopotential and (b), (d) the storm-track features based on the leading EOFs of (a), (b) 700-hPa geopotential and (c), (d) the jet axis distribution for EOF domain the Pacific sector marked by the green outline. Shading and contours in (b), (d) as in Figs. $3 \mathrm{c}$ and $3 \mathrm{~d}$.

from the tropics and due to the east-west asymmetry of the Antarctic continent. This asymmetry leads to more variable sea level pressure in the Amundsen and Bellingshausen Seas, the southeasternmost parts of the South Pacific (LachlanCope et al. 2001).

The anomalies of geopotential and the distribution of the storm-track features are reminiscent of the NAO. The dipole in the geopotential pattern, the shift in the jet axis distribution between a one and a two-jet regime, and the associated shifts in the wave-breaking distribution fit nicely with what has been documented for the North Atlantic (e.g., Franzke et al. 2004; Woollings et al. 2008). These clear parallels between the South Pacific and the North Atlantic indicate that similar dynamical processes might dominate the storm-track variability in these regions. The extent to which an analogy between these ocean basins yields scientific insight, however, remains to be seen.

\section{Summary and conclusions}

We presented strong evidence that SAM predominantly captures variability over and in the vicinity of the Antarctic continent, rather than in the southern midlatitudes. Geopotential-based EOFs of the Atlantic sector only show hemispheric correlations and the annular mode structure when Antarctica is included in the EOF domain (Fig. 1b vs Fig. 1d). Indeed, the entire SAM pattern can be recovered using only the Antarctic sector opening toward 


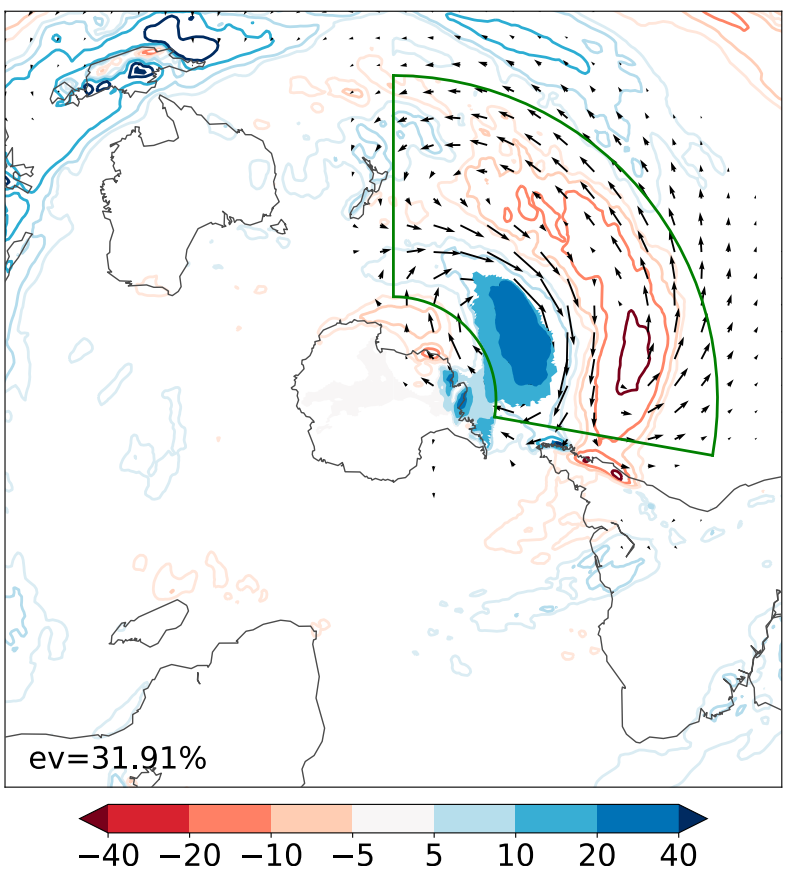

FIG. 8. As in Fig. 5, but for geopotential-based EOFs in the Pacific sector $20^{\circ}-65^{\circ} \mathrm{S}$. Wind arrows follow the same scaling as in Fig. 5, and here the longest wind arrows correspond to about $5 \mathrm{~m} \mathrm{~s}^{-1}$.

the South Atlantic as the EOF domain (Fig. 1f). This result remains valid also for definitions of SAM based on station observations. In this definition, the hemispheric structure of SAM is induced through strong correlations in monthly mean sea level pressure variability among Antarctic coastal stations, with little correlation evident between the island stations in the southern storm track.

These results support the findings of Gerber and Thompson (2017), who also found Antarctica to dominate the SAM pattern. However, our results disagree with Gerber and Thompson (2017) in that the covariability around and over the Antarctic continent cannot be regarded as an artifact of the statistical method. Their interpretation cannot explain the strong correlations in sea level pressure over large distances along the Antarctic coastline as well as the disappearance of the annular mode structure once Antarctica is excluded from the EOF domain. Instead, we propose a physical mechanism, interpreting SAM as a measure of the (de)coupling between Antarctica and the southern midlatitudes. Evidence supporting this interpretation is that SAM correlates strongly with both the poleward heat flux through $65^{\circ} \mathrm{S}$, as well as the average temperatures over the polar cap at $700 \mathrm{hPa}$.

SAM is frequently used to describe variations of the southern midlatitude atmosphere, the Southern Ocean, and the sea ice distribution around Antarctica. Our findings shed new light on many of these studies. Our findings have the strongest implications for studies on the southern midlatitude atmosphere. Here, the documented dissociation of geopotential from storm-track variability as well as the unrelated variability patterns in the different ocean sectors question the suitability of SAM to describe variations in the Southern Hemisphere storm track. Studies on impact on sea ice and ocean circulation (e.g., Hall and Visbeck 2002; Sen Gupta and England 2006) remain valid and topical, as long as they only use SAM as a general description of atmospheric variability. The interpretations of these studies might change, however, when regarding SAM as predominantly subantarctic variability. In particular for studies focusing on sea ice, this shift in interpretation might allow for a more straightforward interpretation of the documented iceatmosphere covariability (Hall and Visbeck 2002; Sen Gupta and England 2006).

SAM is also frequently used in the interpretation of paleoclimate records from the Southern Hemisphere (e.g., Mayewski et al. 2009; Moreno et al. 2014). The suggested new interpretation of SAM as the degree of (de)coupling between Antarctica and the southern midlatitudes might hence impact the interpretation of paleoclimate records, in particular if the proxy used captures predominantly winter variability or if the proxy record is from one of the islands in the southern storm track.

Because of the implications outlined above, our results might also be useful in the design of future studies on Southern Hemisphere coupled and uncoupled variability. Because of the inconsistent dominant types of variability, we recommend future studies be based on variables or diagnostics that are closely related to the problem at hand rather than using geopotential or sea level pressure as a catch-all variable. For studies on the Southern Hemisphere storm track, these could for example be both monthly distributions of weather features and eddy covariances. For studies focusing on surface weather, we recommend to directly base the analysis on, for example, near-surface winds, temperature, or precipitation. For analyses of the coupled variability, the surface momentum and heat exchange might provide the most direct avenue to approach the problem. Finally, as the different ocean sectors of the southern midlatitudes vary largely independently from each other, we recommend basing analyses of midlatitude variability on the respective ocean sector rather than an annular domain.

Following these recommendations, we also investigated alternative approaches to characterize Southern Hemisphere midlatitude variability. Comparing the dominant variability patterns of the storm-track features and of geopotential, we searched for EOF domains in which these dominant patterns yield a consistent picture. For the three ocean basins along the southern storm track, we found only the South Pacific to fulfil this condition. Here, all considered EOFs point toward an NAO-like variability, which is in addition associated with a coherent and 
strong imprint on near-surface winds and precipitation. This Pacific pattern is closely related to the first mode of the Pacific-South America pattern (Lau et al. 1994).

In this paper, we focused exclusively on variability during austral winter. Preliminary results show that some of our findings also apply to summer. However, the suggested (de)coupling mechanism to explain winter SAM likely plays a less dominant role during summer, because the temperature contrast across the Antarctic coastline will be considerably reduced during that season. Further, the described variability pattern in the South Pacific seems to appear also during summer, and it might be complemented by another potentially physical pattern of variability in the south Indian Ocean. These results on the seasonality of Southern Hemisphere variability will be explored in more detail in a followup paper.

In addition to these specific findings, this paper demonstrates the usefulness of applying automated feature detection methods derived for applications in dynamic and synoptic meteorology in the context of climate variability. Demanding consistent variability in geopotential and pertinent features of the storm track, the identification of physically based variability patterns becomes relatively straightforward. This approach also provides a clearer framework for a dynamical interpretation of the variability.

Acknowledgments. We thank Tim Woollings and Camille $\mathrm{Li}$ for insightful discussions. The cyclone track database was kindly prepared and provided by Leonidas Tsopouridis. We thank ECMWF for providing the ERAInterim data. The ERA-Interim data used in this study were obtained directly through the Meteorological Archival and Retrieval System. We thank the British Antarctic Survey for making available the station observations used in Fig. 2, as well as Meteo Chile, the Australian Bureau of Meteorology, and the New Zealand National Institute of Water and Atmospheric Research for the station observations used in Fig. 6. All station observations were obtained through their respective websites.

\section{REFERENCES}

Ambaum, M. H. P., B. J. Hoskins, and D. B. Stephenson, 2001: Arctic Oscillation or North Atlantic Oscillation? J. Climate, 14, 3495-3507, https://doi.org/10.1175/1520-0442(2001)014<3495: AOONAO $>2.0 . \mathrm{CO} ; 2$.

Barnes, E. A., and D. L. Hartmann, 2010: Dynamical feedbacks of the southern annular mode in winter and summer. J. Atmos. Sci., 67, 2320-2330, https://doi.org/10.1175/2010JAS3385.1. , and - 2012: Detection of Rossby wave breaking and its response to shifts of the midlatitude jet with climate change. J. Geophys. Res., 117, D09117, https://doi.org/10.1029/ 2012JD017469.
,,-- D. M. W. Frierson, and J. Kidston, 2010: Effect of latitude on the persistence of eddy-driven jets. Geophys. Res. Lett., 37, L11804, https://doi.org/10.1029/2010GL043199.

Codron, F., 2007: Relations between annular modes and the mean state: Southern Hemisphere winter. J. Atmos. Sci., 64, 33283339, https://doi.org/10.1175/JAS4012.1.

Dee, D. P., and Coauthors, 2011: The ERA-interim reanalysis: Configuration and performance of the data assimilation system. Quart. J. Roy. Meteor. Soc., 137, 553-597, https:// doi.org/10.1002/qj.828.

Ding, Q., E. J. Steig, D. S. Battisti, and J. M. Wallace, 2012: Influence of the tropics on the southern annular mode. J. Climate, 25, 6330-6348, https://doi.org/10.1175/JCLI-D-11-00523.1.

Dritschel, D. G., and M. E. McIntyre, 2008: Multiple jets as PV staircases: The Phillips effect and the resilience of eddytransport barriers. J. Atmos. Sci., 65, 855-874, https://doi.org/ 10.1175/2007JAS2227.1.

Feldstein, S. B., 2003: The dynamics of NAO teleconnection pattern growth and decay. Quart. J. Roy. Meteor. Soc., 129, 901924, https://doi.org/10.1256/qj.02.76.

Franzke, C., S. Lee, and S. B. Feldstein, 2004: Is the North Atlantic Oscillation a breaking wave? J. Atmos. Sci., 61, 145-160, https:// doi.org/10.1175/1520-0469(2004)061<0145:ITNAOA $>2.0$. CO;2.

Gerber, E. P., and G. K. Vallis, 2005: A stochastic model for the spatial structure of annular patterns of variability and the North Atlantic Oscillation. J. Climate, 18, 2102-2118, https:// doi.org/10.1175/JCLI3337.1.

_ , and D. W. J. Thompson, 2017: What makes an annular mode “annular"? J. Atmos. Sci., 74, 317-332, https://doi.org/10.1175/ JAS-D-16-0191.1.

Gillett, N. P., T. D. Kell, and P. D. Jones, 2006: Regional climate impacts of the Southern Annular Mode. Geophys. Res. Lett., 33, L23704, https://doi.org/10.1029/2006GL027721.

Grieger, J., G. C. Leckebusch, C. C. Raible, I. Rudeva, and I. Simmonds, 2018: Subantarctic cyclones identified by 14 tracking methods, and their role for moisture transports into the continent. Tellus, 70A, 1-18, https://doi.org/10.1080/16000870.2018.1454808.

Hall, A., and M. Visbeck, 2002: Synchronous variability in the Southern Hemisphere atmosphere, sea ice, and ocean resulting from the annular mode. J. Climate, 15, 3043-3057, https:// doi.org/10.1175/1520-0442(2002)015<3043:SVITSH > 2.0.CO;2.

Hendon, H. H., D. W. J. Thompson, and M. C. Wheeler, 2007: Australian rainfall and surface temperature variations associated with the Southern Hemisphere annular mode. J. Climate, 20, 2452-2467, https://doi.org/10.1175/JCLI4134.1.

_ E.-P. Lim, and H. Nguyen, 2014: Seasonal variations of subtropical precipitation associated with the southern annular mode. J. Climate, 27, 3446-3460, https://doi.org/10.1175/JCLI-D-13-00550.1.

Hoskins, B. J., and K. I. Hodges, 2005: A new perspective on Southern Hemisphere storm tracks. J. Climate, 18, 4108-4129, https://doi.org/10.1175/JCLI3570.1.

Kidson, J. W., 1988: Interannual variations in the Southern Hemisphere circulation. J. Climate, 1, 1177-1198, https://doi.org/ 10.1175/1520-0442(1988)001<1177:IVITSH > 2.0.CO;2.

Kidston, J., J. A. Renwick, and J. McGregor, 2009: Hemisphericscale seasonality of the southern annular mode and impacts on the climate of New Zealand. J. Climate, 22, 4759-4770, https:// doi.org/10.1175/2009JCLI2640.1.

Lachlan-Cope, T. A., W. M. Connolley, and J. Turner, 2001: The role of the non-axisymmetric Antarctic orography in forcing the observed pattern of variability of the Antarctic climate. Geophys. Res. Lett., 28, 4111-4114, https://doi.org/10.1029/2001GL013465. 
Lau, K.-M., P.-J. Sheu, and I.-S. Kang, 1994: Multiscale low-frequency circulation modes in the global atmosphere. J. Atmos. Sci., 51, 1169-1193, https://doi.org/10.1175/1520-0469(1994)051<1169: MLFCMI $>2.0 . \mathrm{CO} ; 2$.

Limpasuvan, V., and D. L. Hartmann, 1999: Eddies and the annular modes of climate variability. Geophys. Res. Lett., 26, 3133 3136, https://doi.org/10.1029/1999GL010478.

Marshall, G. J., 2003: Trends in the southern annular mode from observations and reanalyses. J. Climate, 16, 4134-4143, https:// doi.org/10.1175/1520-0442(2003)016<4134:TITSAM>2.0.CO;2.

Mayewski, P. A., and Coauthors, 2009: State of the Antarctic and Southern Ocean climate system. Rev. Geophys., 47, RG1003, https://doi.org/10.1029/2007RG000231.

Moreno, P. I., I. Vilanova, R. Villa-Martínez, R. D. Garreaud, M. Rojas, and R. De Pol-Holz, 2014: Southern Annular Mode-like changes in southwestern Patagonia at centennial timescales over the last three millennia. Nat. Commun., 5 , 4375, https://doi.org/10.1038/ncomms5375.

Murray, R. J., and I. Simmonds, 1991a: A numerical scheme for tracking cyclone centres from digital data. Part I: Development and operation of the scheme. Aust. Meteor. Mag., 39 (3), 155-166.

$\ldots$, and 1991b: A numerical scheme for tracking cyclone centres from digital data. Part II: Application to January and July general circulation model simulations. Aust. Meteor. Mag., 39 (3), 167-180.

Neu, U., and Coauthors, 2013: IMILAST: A community effort to intercompare extratropical cyclone detection and tracking algorithms. Bull. Amer. Meteor. Soc., 94, 529-547, https:// doi.org/10.1175/BAMS-D-11-00154.1.

O'Kane, T. J., D. P. Monselesan, and J. S. Risbey, 2017: A multiscale reexamination of the Pacific-South American pattern. Mon. Wea. Rev., 145, 379-402, https://doi.org/10.1175/MWR-D-16-0291.1.

Reason, C. J. C., and M. Rouault, 2005: Links between the Antarctic Oscillation and winter rainfall over western South Africa. Geophys. Res. Lett., 32, L07705, https://doi.org/10.1029/ 2005 GL022419.
Rivière, G., 2009: Effect of latitudinal variations in low-level baroclinicity on eddy life cycles and upper-tropospheric wavebreaking processes. J. Atmos. Sci., 66, 1569-1592, https:// doi.org/10.1175/2008JAS2919.1.

Sen Gupta, A., and M. H. England, 2006: Coupled ocean-atmosphereice response to variations in the southern annular mode. J. Climate, 19, 4457-4486, https://doi.org/10.1175/JCLI3843.1.

Silvestri, G. E., and C. S. Vera, 2003: Antarctic Oscillation signal on precipitation anomalies over southeastern South America. Geophys. Res. Lett., 30, 2115, https://doi.org/10.1029/ 2003 GL018277.

Simmonds, I., C. Burke, and K. Keay, 2008: Arctic climate change as manifest in cyclone behavior. J. Climate, 21, 5777-5796, https://doi.org/10.1175/2008JCLI2366.1.

Spensberger, C., T. Spengler, and C. Li, 2017: Upper-tropospheric jet axis detection and application to the boreal winter 2013/14. Mon. Wea. Rev., 145, 2363-2374, https://doi.org/10.1175/ MWR-D-16-0467.1

Thompson, D. W. J., and J. M. Wallace, 2000: Annular modes in the extratropical circulation. Part I: Month-to-month variability. J. Climate, 13, 1000-1016, https://doi.org/10.1175/15200442(2000)013<1000:AMITEC > 2.0.CO;2.

- and J. D. Woodworth, 2014: Barotropic and baroclinic annular variability in the Southern Hemisphere. J. Atmos. Sci., 71, 1480-1493, https://doi.org/10.1175/JAS-D-13-0185.1.

Wernli, H., and C. Schwierz, 2006: Surface cyclones in the ERA-40 dataset (1958-2001). Part I: Novel identification method and global climatology. J. Atmos. Sci., 63, 2486-2507, https:// doi.org/10.1175/JAS3766.1.

Woollings, T., B. Hoskins, M. Blackburn, and P. Berrisford, 2008: A new Rossby wave-breaking interpretation of the North Atlantic Oscillation. J. Atmos. Sci., 65, 609-626, https:// doi.org/10.1175/2007JAS2347.1.

- and Coauthors, 2018: Daily to decadal modulation of jet variability. J. Climate, 31, 1297-1314, https://doi.org/10.1175/ JCLI-D-17-0286.1. 